\title{
Soymilk protein detection in milk- A review
}

\author{
Priyae Brath Gautam, Rajan Sharma, Suvartan Ranvir, Kamal Gandhi and Bimlesh Mann
}

Received: 03 March 2019 / Accepted: 19 March 2019 / Published online: 22 June 2019

(C) Indian Dairy Association (India) 2019

\begin{abstract}
Milk being considered as a complete food can also be easily adulterated by a large number of adulterants. Such type of adulteration deteriorates its quality and can affect the health of the consumers. Processing such type of adulterated milk can affect certain processing parameters in the dairy industry thus affecting the quality of final products. A large number of adulterants in milk have been used worldwide and have been reported like water, urea, carbohydrates, foreign proteins, vegetable or animal fats, melamine and so on. Unscrupulous producers even add hazardous substances to gain profits. This review focuses on the detection of soy proteins by different methods like RP-HPLC, UHPLC, SDS-CE, SDS-PAGE, SDS-PAGE/ MS, FPLC, NIR spectroscopy, FTIR, lateral flow assay, biosensors, LC/MS-MS that have been developed and used since last 25 years. From long and time-consuming electrophoretic to biosensor-based methods, this review will provide a clear understanding of the various assays.
\end{abstract}

Keywords: Adulteration, FTIR, Gold nanoparticles, Polyacrylamide gel electrophoresis, Reverse phase high-pressure liquid chromatography, Soyabean, Soymilk

Priyae Brath Gautam, Rajan Sharma ( $\square$ ), Suvartan Ranvir, Kamal Gandhi and Bimlesh Mann

Division of Dairy Chemistry, ICAR-National Dairy Research Institute, Karnal-132 001 (Haryana), India

E-mail:rajansharma21@gmail.com;Phone: +91-9416120181

\section{Introduction}

Based on various scientific literature on adulteration of food, milk is ranked next to olive oil as the most adulterated food commodity (Jablonski et al. 2014). In order to gain maximum profit and to bridge the gap between demand and supply of milk during lean season, the unscrupulous producers adulterate milk with a number of adulterants. Apart from its fat content, nitrogen content of milk is also used as a parameter for determining the price of milk (Gautam et al. 2017). United States Pharmacopeial Convention has advocated the use of improved methods to detect the economically motivated adulteration, as conventional nitrogen assays like Kjeldahl and Dumas are not much effective methods of detection (Moore et al. 2010). In 2002 and 2007, EU has reported use of plant proteins as adulterants for skimmed milk powder (SMP) (Scholl et al. 2014). The low prices of plant proteins make them potential adulterants in SMP. Soyabean is a cheap and easily accessible source of plant protein in contrast to milk proteins (Luykx et al. 2007). Soymilk added to bovine milk is being sold as fluid milk (Sharma et al. 2009). A variety of soyabean products like soyabean juices, soyabean flour, textured soyabean, soyabean infant formula are available (Saz \& Marina, 2007). Soy protein is also used in milk mimetics like simulated yoghurt, coffee whiteners and frozen desserts, thus a major potent adulterant (Haasnoot et al. 2001). In spite of its nutritional properties, soyabean is considered as an allergen (Marina et al. 2006). It is considered as one of the major eight food allergens (Wang et al. 2015 ) and its presence in food poses potential risk to some allergenic people especially infants (Poms et al. 2004, Azad \& Ahmed, 2016) as their gut barrier is underdeveloped (Rozenfeld et al. 2002). Glycinin, a major soy protein has been reported to affect intestinal function, immune function and promote diarrhea (Wang et al. 2015). Soymilk contains anti-nutritional factors like trypsin inhibitor, proteinase inhibitor, tannins, alkaloids, so its absence is to be ensured to ascertain consumer health (Jaiswal et al. 2015). Soy protein is statutorily defined as allergens by FALCPA (Food Allergen Labeling and Consumer Protection Act) as per US law (Scholl et al. 2014). Keeping in view the interest and to protect the consumer, EU Directive (2007) instructed strict labeling of food commodities containing soyabean and its products regardless of its mass function in the product (Gautam 
et al. 2017). In spite of remarkable success achieved in the field of chemistry of major soy proteins, the quantitative determination of glycinin (11S) \& $\beta$-conglycinin (7S) is a major problem especially when mixed in low proportions with other products (Tapia et al. 1999). In addition, processing conditions modifies the native state of the soy proteins thereby affecting their determination (Garcia \& Marina, 2006). Processing of soymilk adulterated bovine milk can affect certain downstream processes in the dairy industry (Gautam et al. 2017). This review discusses in detail various analytical approaches employed to detect soymilk adulteration in milk.

\section{Chromatographic methods}

\section{HPLC/UHPLC}

Pure SMP was differentiated from SMP adulterated with soy protein isolates (SPI) using UHPLC-UV fingerprinting technique employing water $+0.1 \%$ trifluoroacetic acid (TFA) and acetonitrile $+0.1 \%$ TFA as mobile phase at a wavelength of $215 \mathrm{~nm}$ and a column temperature of $50^{\circ} \mathrm{C}$. The samples were prepared by adding a denaturing buffer consisting of $6 \mathrm{M}$ guanidine $\mathrm{HCl}, 20$ $\mathrm{mM}$ dithiothreitol, $5 \mathrm{mM}$ trisodium citrate followed by vortexing, dilution, refrigeration and centrifugation. The chromatogram for SMP used data points from the entire chromatogram excluding 0 3 min retention window because of very high solvent front peak. The retention window from 3-35 min was taken for further statistical analysis. SMP adulterated with SPI at 3\% (w/w) was differentiated from point-by-point t-test comparison of the chromatogram, while adulteration up to $1 \%$ was detectable using Soft Independent Modeling of Class Analogy (SIMCA) analysis at $95 \%$ confidence levels. Using appropriate statistical tools (Q statistic and t-test), it was possible to correctly classify adulteration of SMP with SPI at 1 and 3\% levels, respectively, while minimizing false classifications of authentic SMP (Jablonski et al. 2014). The presence of soybean sugars such as sucrose, raffinose, stachyose in suspected milk samples have been used for detection of soymilk in milk. The sugars from milk samples were extracted by using Carrez I, Carrez II and 20\% acetonitrile followed by sonication of the filtrates for degassing. Use of acetonitrile facilitated protein precipitation so that a clear filtrate could be obtained for its further application in HPLC. The process for the extraction of sugars was not affected by the use of $20 \%$ acetonitrile. The sugars were separated based on their chemistry with $\mathrm{NH}_{2}$ column using acetonitrile and water in 70:30 ratio as mobile phase at a flow rate of $1 \mathrm{ml} / \mathrm{min}$ using refractive index detector. The temperature of the column and RI was maintained at $40^{\circ} \mathrm{C}$. Buffalo milk/ bovine milk exhibited a major peak corresponding to lactose which was very broad and thus masked the peaks of sucrose and raffinose. The peak for lactose was absent in pure soymilk. Raffinose, sucrose and stachyose peak were absent in bovine or buffalo milk. Sucrose and raffinose peak were masked by the peak of lactose in the case of adulterated milk at 5\% soymilk. However, well resolved stachyose peak (soymilk sugar) appearing at 12 min retention time can be used as a marker for detection of adulteration of milk with soymilk up to $5 \%$ levels (Fig 1) (Sharma et al. 2009). A linear binary gradient of acetonitrile-water-trifluoroacetic acid at a flow rate of $5 \mathrm{ml} / \mathrm{min}$ at $254 \mathrm{~nm}$ (because maximum absorption of phenylalanine is observed at this wavelength and it has been shown to be adequate for detection of soy proteins) (Garcia et al. 1998 \& Garcia et al. 2000) was employed to detect soyabean proteins adulteration in cow, goat and ewe milk using perfusion reversedphase high-performance liquid chromatography. In this method, SPI were used for sample preparation. Milk diluted with Milli-Q water was filtered through $0.45-\mu \mathrm{m}$ pore size filters followed by mixing with SPI solutions. The spiked milk was centrifuged and the supernatant was stored at $4^{\circ} \mathrm{C}$ before using for HPLC analysis. The retention time for goat and ewe milk proteins was slightly higher than that for cow milk proteins. Soyabean proteins eluted in eight peaks but the last peak coeluted with the second peak of the milk proteins. Fresh whole and defatted cow milk showed similar recoveries. Milk adulterated with soyabean proteins upto $30 \mu \mathrm{g} / \mathrm{ml}$ was detected using the above method within $2 \mathrm{~min}$ (Fig 2). Maximum matrix interferences were observed in case of fresh milk which was independent of the fat content and its source i.e. animal species, while liquid, defatted cow's milk and liquid semi defatted goat milk showed minimum matrix interference which was quantitatively evaluated by the recoveries obtained by using external standard and standard addition methods (Espeja et al. 2001). Perfusion chromatography enables separation of the biomolecules rapidly without affecting the resolution (Afeyan et al. 1990 \& Fulton et al. 1991) as the stationary phase particles allow a better interaction with the solute/analyte molecules (Espeja et al. 2001). A method using reversed phase- perfusion chromatography was used to detect soyabean protein detection in milk, cheese and yoghurt. $0.1 \%$ TFA in water and $0.1 \%$ TFA in acetonitrile were used as mobile phase keeping the flow rate at 3 or $5 \mathrm{ml} / \mathrm{min}$ at a temperature of $60^{\circ} \mathrm{C}$ and detection carried at 254 $\mathrm{nm}$. Using calibration curve for soy proteins, detection of soy proteins in adulterated dairy products could be quantified by interpolation of the area under the soy protein corresponding peaks. Least square regression analysis was done to obtain the linearity of the calibration curve. Sample for cheese was prepared by extracting the cheese spiked with SPI with water followed by homogenization, centrifugation and filtered. Soy proteins eluted at the start while cheese proteins eluted at the end. Soy proteins in fresh cheeses and in ripened cheeses were detected upto a level as low as $0.04 \% \& 0.1 \% \mathrm{w} / \mathrm{w}$, respectively. Results obtained for fresh or semi ripened cheese were free from matrix interferences unlike for soft and ripened cheese. Recoveries obtained for such type of cheeses were improved by standard additions calibration method. Powdered milks were adulterated with soyabean proteins from different sources at different levels. These milks were then further subjected to pasteurization and UHT treatment. The soy protein content determined in UHT milk was lower than that of pasteurized milk due to the intense heat treatment in case of the 

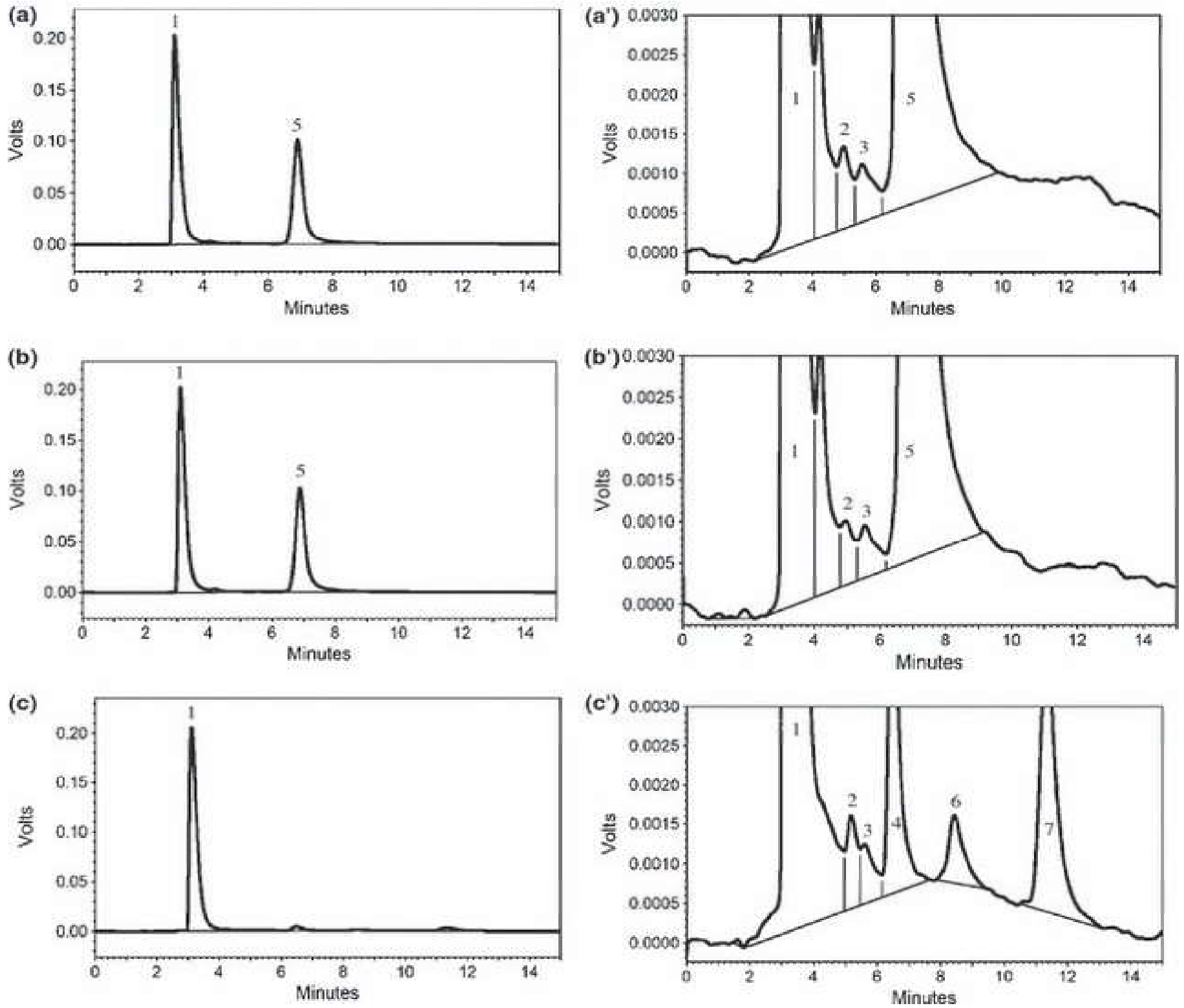

Fig. 1 Separation of sugars from bovine, buffalo and soymilk using HPLC. (a) Bovine milk (b) buffalo milk (c) soymilk. a', b' and c' correspond to high-resolution chromatogram of bovine, buffalo and soymilk respectively. Peak 1- solvent; 2- fructose; 3- glucose D galactose; 4- sucrose; 5- lactose; 6- raffinose and 7- stachyose. Adapted from Sharma et al. (2009) (Figure used with permission)

former. Different processing conditions used for the manufacture of cheese, yoghurt and enteral formula affected the determination of soy proteins (Garcia \& Marina, 2006). Krusa et al. (2000) designed a RP-HPLC based method for quantification of soyabean proteins in bovine milk. A linear binary gradient of acetonitrilewater- $0.1 \%$ TFA was used. The flow rate was maintained at $1 \mathrm{ml} /$ min and the column temperature was maintained at $50^{\circ} \mathrm{C}$. Standard solutions for SPI were prepared within range of 0.5-3.5 mg/ml. On comparing the chromatograms of the aqueous solutions of SPI, defatted bovine milk and bovine milk containing soy protein, it was observed that first peak of SPI overlapped with the peak of bovine milk while the rest three peaks of SPI were separate, so these peaks were considered for quantitative analysis. The gradient was also shortened to reduce the analysis time. Effects of the matrix were studied for samples spiked with SPI and the results revealed that this method also suffered from matrix interferences. These effects became more noticeable when the milk concentration was increased. Limit of detection for this method was $13 \mu \mathrm{g}$ of protein/ $\mathrm{g}$ of bovine milk. Sensitivity for protein separations and their improved resolutions can be achieved by using $\mu$-HPLC. In this method, Marina et al. (2006) used a capillary column having an internal diameter of $150 \mu \mathrm{m}$, 


\section{POWDERED COW MILK}

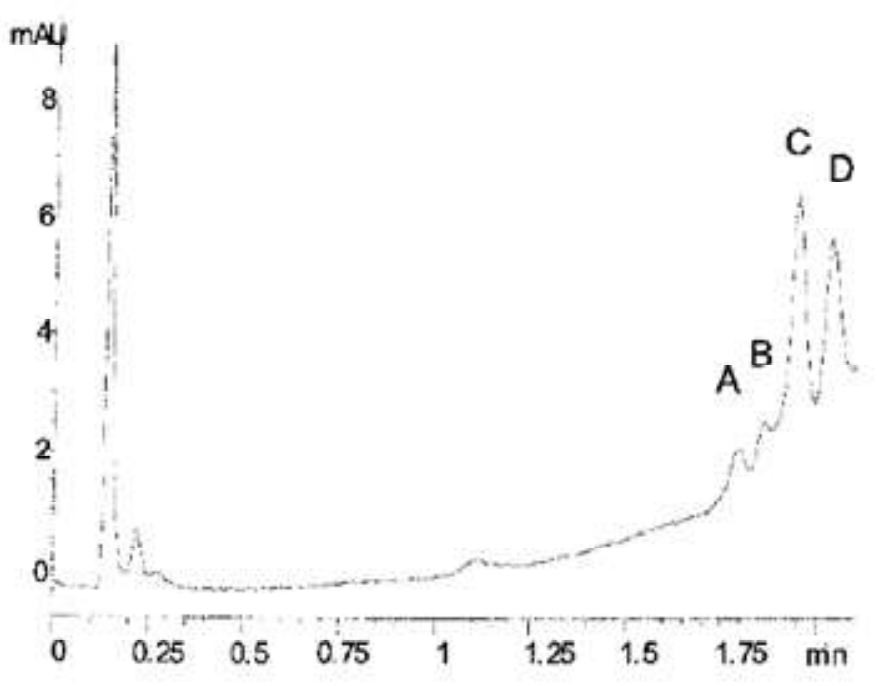

\section{POWDERED COW MILK SPIKED WITH SOYBEAN PROTEINS}

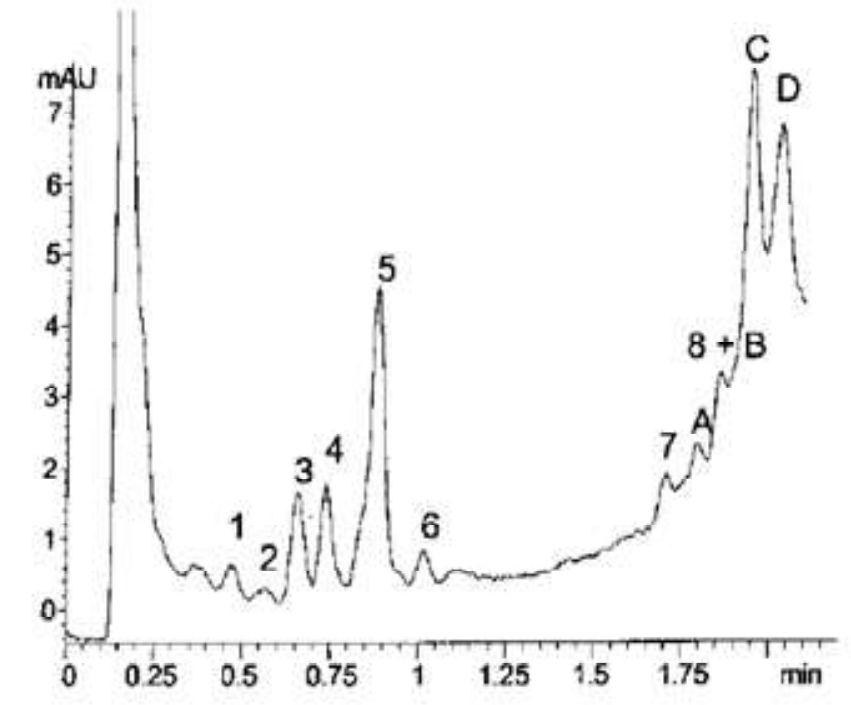

Fig. 2 Separation of cow milk and soy proteins using perfusion reverse phase high-performance liquid chromatography. Peak identification: 1-8, soyabean proteins; A-D, cow's milk proteins. Adapted from Espeja et al. (2001) (Figure used with permission)

which was filled by Genesis C18 stationary phase. Water and acetonitrile gradients coupled with TFA and acetic acid as ion pairing reagents were used and detection was carried out at 254 $\mathrm{nm}$. The supernatant obtained after spiking of soy proteins in milk followed by centrifugation was injected in the chromatographic system. A number of gradients were used in order to decrease the analysis time from $42 \mathrm{~min}$ but it lead to the loss of resolution, thus water-acetonitrile-TFA gradient was used. The column used in the study could resolve the separation of soy proteins from milk proteins along with wheat, corn and rice proteins thus indicating good selectivity in separation. Also, this method indicated its efficacy for detecting soy proteins in commercial products.

\section{Immunoassays}

Hasnoot et al. (2001) developed a biosensor immunoassay for detecting non milk proteins in SMP. BIACORE 3000, an optical biosensor, based on the principle of surface plasmon resonance (SPR) was used in this method. Affinity purified antibodies against pea, soy and wheat proteins were immobilized on the biosensor chip. Labeling of the reagents was not required in this method, thus making it as a rapid detection technique, suitable for highthroughput screening. Nonmilk protein isolates (soy, pea, wheat) were spiked in skim milk at 0, 1,2 and 5\% levels. Spiked milk was then subjected to a number of treatments before pasteurization/ UHT and spray drying. As low as $0.1 \%$ of plant proteins (soy, pea and wheat) in powdered milk were detectable within $5 \mathrm{~min}$.
Results obtained for UHT milk differed from pasteurized milk as the heat treatment might have altered their antigenic properties or may have reduced their solubility. The antibodies got bound to other proteins like nuts, pumpkin seed, marrowfat, brown bean, rye, barley etc. This indicated that this method can be used to detect a wide range of non-milk proteins. The chip was reuseable and worked even after 650 injections. An immuno-diffusion method which detected soymilk up to $1 \%$ within $12 \mathrm{~h}$ was developed using commercially available anti-soy antibodies. The anti-soy antibodies did not showed any cross-reactivity against milk proteins. Adulterated milk samples formed precipitating lines with anti-soy antibodies (Sharma et al. 2010). Using an ELISA based technique, the quantitative and qualitative detection of soy milk/ protein in bovine milk was done. The soy proteins were slightly modified so as to react with the raised antibody. Caseins showed marked cross-reactivity against the anti soy antibody which made the application of this method slightly difficult in dairy products. The cross-reacting components were removed by partial purification of the anti soy antiserum by affinity chromatography. This method detects soy proteins up to $1 \%$ level in soy milk adulterated milk (Hewedy \& Smith, 1990). Haasnoot \& Jolanda (2007) developed a luminex based triplex immunoassay which involved use of affinity purified polyclonal antiserum against soy proteins. Inhibition assay was used for the detection as it was much easily distinguishable than sandwich method. Soya proteins, if present interacted with the antibodies immobilized on the sensor surface which were further detected. The time required for analysis was $5 \mathrm{~min}$, and its limit of 


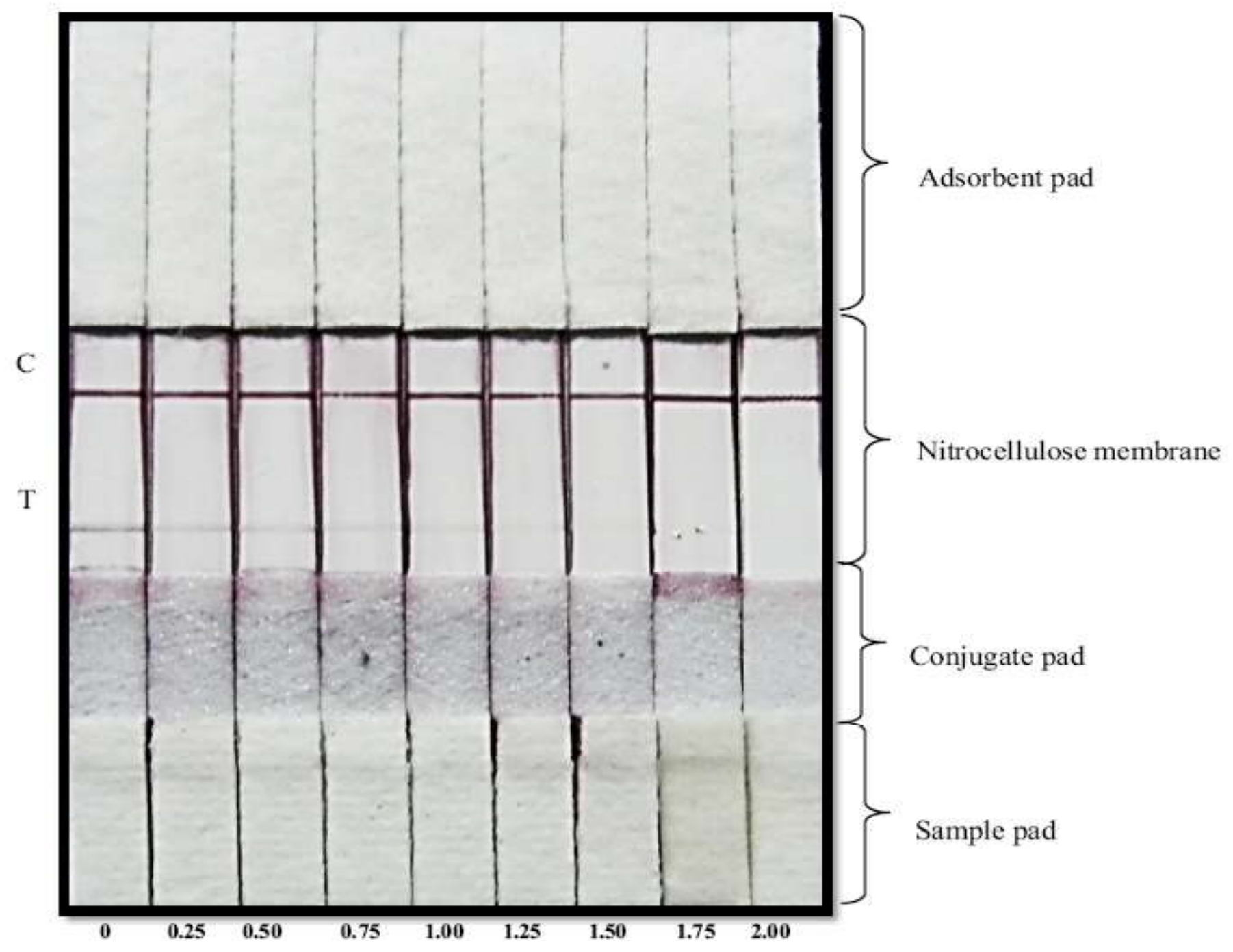

Fig. 3 Detection of soymilk in whole milk spiked with soymilk at various concentrations (\%) using lateral flow assay. C, control line; T, test line. Adapted from Gautam et al. (2017) (Figure used with permission)

detection in milk powder was reported to be below $0.1 \%$. When compared to ELISA, this technique was more reproducible and less time consuming with a wide range of measurement (Dasso et al. 2002). At present the lateral flow based assay has become an attractive tool in the field of analytical chemistry. This method has been used to detect soymilk adulteration in milk (Gautam et al. 2017). Glycinin being a predominant soy protein, monoclonal and polyclonal antibodies against glycinin were raised in mouse and rabbit, respectively and the former exhibited high specificity for glycinin. Gold-labeled monoclonal antibodies were applied on conjugate pad, polyclonal antibody was applied on test line while control line had anti-mouse antibody. Milk samples having minimum $0.69 \mathrm{mg} / \mathrm{kg}$ of glycinin produced red color/ band on the test line while its absence indicated below detection levels (Wang et al. 2015). Another method was developed based on lateral flow technique by Gautam et al. (2017) in which the commercially available rabbit anti-soy antibodies raised in rabbit was conjugated with gold nanoparticles (AuNPs). In this method, the test and control lines were immobilized by soymilk and antirabbit antibody, respectively. AuNPs prepared by citrate reduction method were analyzed for their stability and size. They have the property of exhibiting plasmon resonance peak and the same property was reflected by the prepared AuNPs at $520 \mathrm{~nm}$. The size of AuNPs used for lateral flow assay was $28.59 \mathrm{~nm}$ and their zeta potential was $-38.3 \mathrm{mV}$. The results indicated that the AuNPs were quite stable and thus suitable to be used in lateral flow assay. The AuNPs were conjugated to the anti-soy in borate buffer. Antibody conjugated AuNPs were applied on the conjugate pad and dried before application of the sample. Appearance of red band on the test line indicated pure milk while 


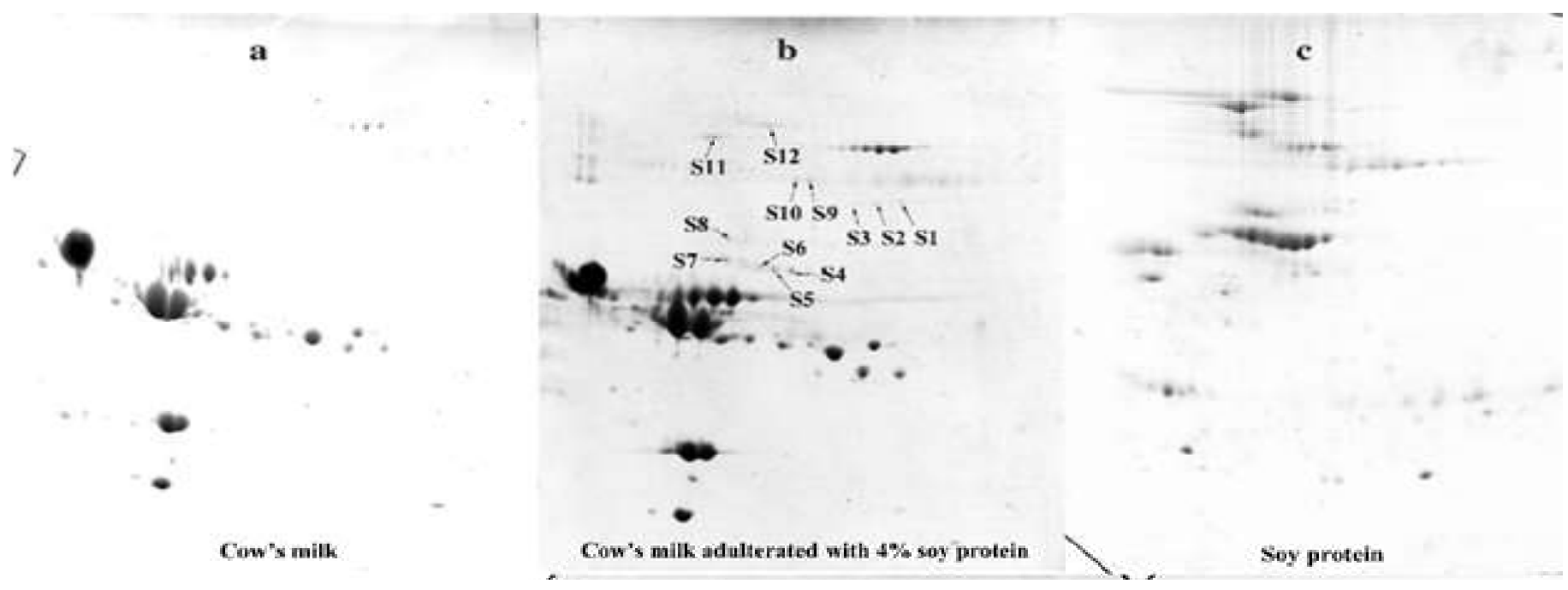

Fig. 4 Two-dimensional electrophoresis maps of protein spots of cow's milk (a), cow's milk adulterated with 4\% soymilk (b), Soy protein (c). Adapted from Yang et al. (2018) (Figure used with permission)

its absence indicated milk adulterated with soy. The presence of red band on the control line indicates validation of the assay. The sample applied on the sample pad travelled due to the capillary action so in order to obtain a better capillary action in case of whole milk, EDTA was added to the milk for disruption of casein micelles. The soymilk detection limit was $1.75 \%$ in whole milk (Fig 3).

\section{Electrophoresis based methods}

The property of milk proteins being soluble and plant proteins being insoluble in the tetraborate-EDTA buffer was exploited for the detection of soy proteins adulteration by Sodium Dodecyl Sulphate- Capillary Gel Electrophoresis. Treatment with tetraborate-EDTA buffer ensured selective removal of milk proteins thus enhancing the detection even at low proportions of plant proteins. The precipitated plant proteins were dissolved in Tris-HCl buffer in the presence of sodium dodecyl sulphate (SDS) and a reducing agent to disrupt and uncoil the proteins. The electrophoresis was carried at $25^{\circ} \mathrm{C}$, with increasing the voltage linearly from $2 \mathrm{kV}$ to $7 \mathrm{kV}$ within a period of $1.7 \mathrm{~min}$ followed by a constant voltage of $7 \mathrm{kV}$. The detector was set at $214 \mathrm{~nm}$. The peaks which corresponded to the subunits of glycinin a major soy protein were used for quantitation as these peaks were identified by Sodium Dodecyl SulphatePolyacrylamide gel electrophoresis (SDS-PAGE) pattern of soy proteins in previous work (Molina et al. 1998 \& Perez et al. 2000). A LOD of $1 \%$ soy protein in total protein was established in low heat milk powder. As the study conducted was interlaboratory, so Cochran and Grubbs test was applied to the obtained data. Since certain milk processing treatments like homogenization, heat treatment, spray drying dramatically reduced recovery of milk and plant proteins as proper separation between plant and milk proteins was not achieved, so capillary electrophoresis being a sensitive method was used for analysis (Manso et al. 2002). Another method used for detection of soy protein in milk involved resolving of milk and soy proteins on $12.5 \%$ acrylamide gel using Laemmli buffer. The proteins of cow and soy differed in their molecular weight. Certain characteristic bands of proteins having molecular weight of about 20,50 and $95 \mathrm{kDa}$ suggested that these proteins were present in soymilk but absent in cow milk. The presence of these characteristic bands of soy proteins were used as a marker for the detection of soymilk in whole milk for up to $5 \%$ levels (Sharma et al. 2010). Tapia et al. (1999) detected soy proteins in milk protein up to $1 \%$ level. The results indicated that the detection could be made on the basis of the basic subunits of glycinin and $\alpha$ and $\alpha$ subunits of $\beta$-conglycinin. So they can be used as the markers for the detection of soy proteins in milk as the acid subunits of glycinin and the $\gamma, \beta$ subunits of $\beta$ conglycinin coincided with caseins because of their similar molecular weights. The use of tetraborate-EDTA buffer minimized the interferences caused by milk proteins by removing them and the losses occurred during extraction of soy proteins was negligible. Similar electrophoretic patterns were observed in all of the commercial soy protein preparations except in the case of hydrolyzed products. Thus, it can be concluded that the main soy protein indicators can be detected by this method regardless of their composition and processing conditions. This method was less time consuming than SDS-PAGE but gave poor resolution. Urea alkaline polyacrylamide gel electrophoresis and SDS-PAGE were used for qualitative and quantitative detection of soymilk in pasteurized bovine milk by Hewedy and Smith (1989). Soymilk spiked bovine milk was freeze dried and the samples were mixed in the buffer. Fast protein liquid chromatography (FPLC) technique was employed for the detection purpose by maintaining a flow rate of $1 \mathrm{ml} / \mathrm{min}$ and monitoring the eluate at $254 \mathrm{~nm}$ using a gradient of loading buffer and sodium chloride as a mobile phase. FPLC reduced the LOD of soymilk in pasteurized 


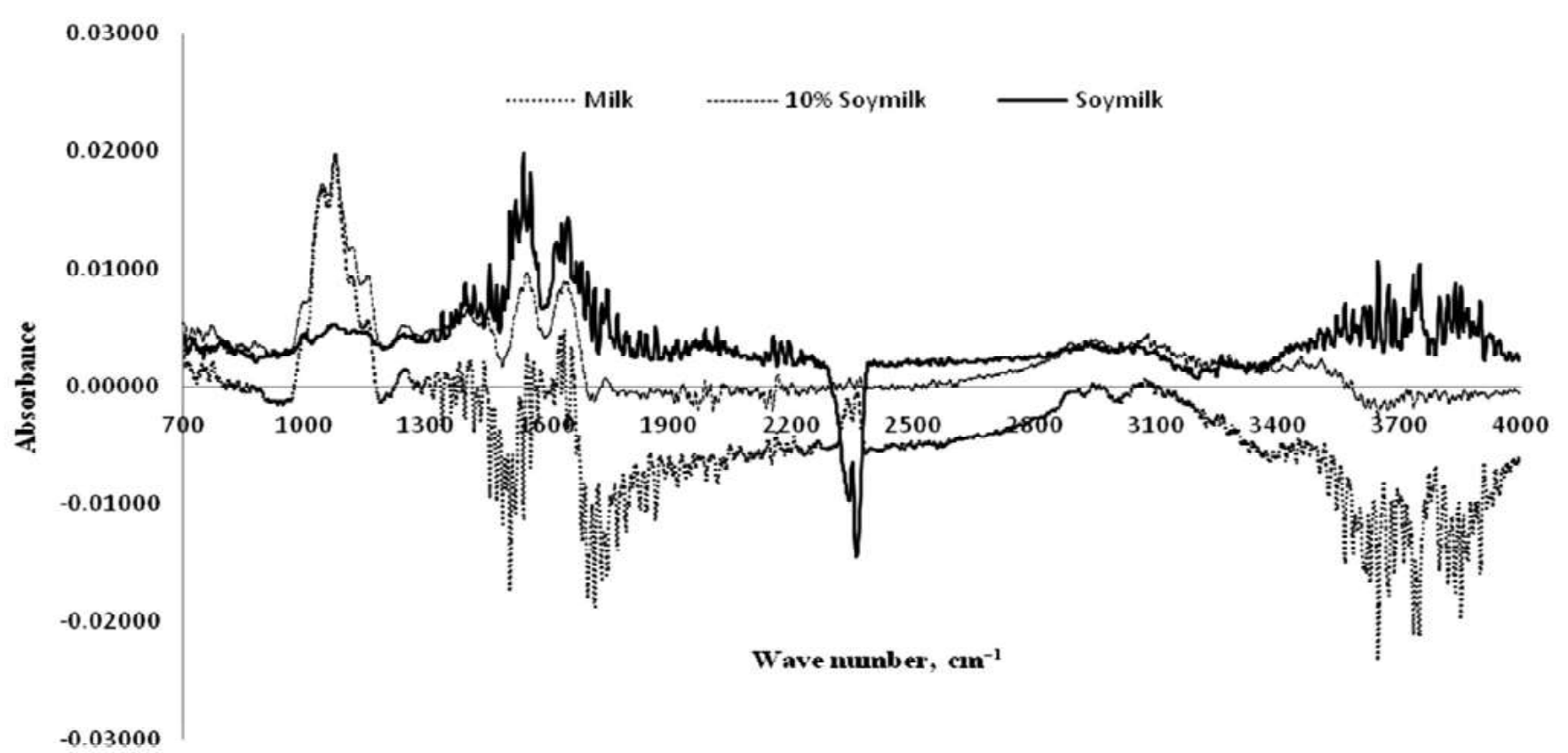

Fig. 5 Detection of soymilk in milk using FTIR, spectra of milk, soymilk (SM) and adulterated milk (10\% soymilk) in the wave number range of 4000-700 $\mathrm{cm}^{-1}$. Adapted from Jaiswal et al. (2015) (Figure used with permission)

bovine milk from $5 \%$ as detected by SDS-PAGE to $1 \%$. Results obtained by SDS-PAGE were difficult to quantify and the analysis was time-consuming, thus FPLC was employed for detection as it is a fully automatic technique with a greater and faster rate of analysis. Two-dimensional gel electrophoresis coupled with mass spectroscopy was used to detect soy proteins in milk. Milk samples were spiked with soy proteins at 2,4 and $8 \%$ of total proteins. The stained gels were destained, dried and were subjected to tryptic digestion. The digested samples were subjected to and were analyzed by matrix-assisted laser desorption ionization-time of flight mass spectrometry (MALDITOF-MS) for the identification of marker proteins to be used for adulterant detection. On analyzing the gel maps with successive mass spectroscopy containing soy proteins showed spots corresponding to $\beta$-conglycinin and glycinin. The identified soy protein spots had a higher molecular weight than milk proteins. $\beta$-conglycinin and glycinin were identified as the markers for milk adulteration with soy proteins. Soymilk added up to $4 \%$ in milk can be detected by this method (Fig 4) (Yang et al. 2018).

\section{Spectroscopic methods}

Optical property of sugars present in soymilk and whole milk were exploited for detection of presence of soymilk in milk. Lactose is the principle sugar in bovine and buffalo milk (Fox et al. 1998). Stachyose, raffinose and sucrose are present in soymilk and absent in buffalo and bovine milk (Wang et al. 2003). These sugars present in whole milk and soymilk are capable of rotating the plane polarized light clockwise or anticlockwise depending on the functional groups attached to the chiral carbon. Protein free filtrates of bovine, buffalo, soymilk and milk adulterated with soymilk were analyzed using $200 \mathrm{~mm}$ polarimeter tube at a wavelength of $589.3 \mathrm{~nm}$ at $20^{\circ} \mathrm{C}$. Soymilk indicated a lower optical rotation than cow and buffalo milk whereas there was no significant difference in the optical rotation of cow and buffalo milk. Results showed that the decrease in the optical rotation was directly proportional to the increase in the soymilk content in cow or buffalo milk. Soymilk adulterated up to $10 \%$ can be detected by this method in 45 minutes (Sharma et al. 2010). Near Infrared Spectroscopy being a quick and rapid technique was used for the detection of soy, pea and wheat isolates in milk powder. This technique was advantageous over electrophoretic and immunological methods as it requires no sample preparation and is convenient to use. The spectra were taken at room temperature and results were processed by a suitable statistical tool (sesame software) for the selection of the most significant wavelengths. Data pretreatments were also applied and measured by Partial Least Squares Regression, Principal Component Regression and Multiple Linear Regression. Skim milk was spiked with two different SPI followed by homogenization and pasteurization or UHT treatment followed by spray drying. These spray-dried samples were used for further analysis. Multiple Linear Regression was applied to the first derivative of the NIR absorbance values showed best relationship characterized by low SEC value and minimum outliers. A range of 2000-2400 nm showed most imperative differences amongst the samples and no sample overlapping was observed (Maraboli et al. 2002). Fourier Transform Infrared (FTIR) spectroscopy, a rapid technique 
used for accessing quality of milk has been used for detection of soymilk in milk. Samples of milk adulterated with pasteurized unflavored soymilk were prepared at different levels and were stored at temperatures ranging from $15-30^{\circ} \mathrm{C}$. The spectra were taken in the wave number ranging from $4000-500 \mathrm{~cm}^{-1}$ (Fig 5). Clear differences were observed in the spectra of milk and soymilk in the regions of $1639-1613 \mathrm{~cm}^{-1}$, with soymilk showing higher absorption than milk because of presence of a higher amount of secondary structures in soy protein. Milk showed higher absorption values than soymilk in the spectral range of 1089$1058 \mathrm{~cm}^{-1}$. These differences were due to the presence of phosphate groups covalently bound to the caseins in milk. Amide-I, II and III were present in higher amount in soymilk than milk and exhibited a higher absorption values in the spectral range of $1680-1631 \mathrm{~cm}^{-1}, 1560-1553 \mathrm{~cm}^{-1}$ and $1472-1239 \mathrm{~cm}^{-1}$ respectively. Samples of adulterated milk stored at $20^{\circ} \mathrm{C}$ exhibited better results as it had lowest particle depression index. SIMCA class projection helped in differentiating between pure and adulterated milk on the basis of the spectra generated by FTIR. Except at 6\% level, correct classification was done at different levels of soymilk in the range of $1639-1635 \mathrm{~cm}^{-1}$. The ATR-FTIR method was able to detect soymilk in milk as low as $2 \%$ level $(\mathrm{p}<0.05)$ with minimum sample preparation and data treatments (Jaiswal et al. 2015). UPLC-quadrupole time-of-flight-mass spectrometric (UPLC-qTOF-MS) proteomics model combined with chemometrics was used for in the detection of raw milk adulterated with plant proteins. The extracted proteins from the adulterated milk samples were treated by trypsin to convert proteins to peptides. This digested solution was injected to UPLCMS and analyzed over a period of $78 \mathrm{~min}$. The elution pattern of plant peptides could be distinguished from that of milk from 25 to 27, 27 to 32,36 to 40 , and 41 to $45 \mathrm{~min}$ due to the dissimilar polarity of peptides. Protein-Lynx Global Server (PLGS) was used to analyze UPLC-MS spectra to identify proteins in the samples. Twenty six major proteins were identified out of which six were milk proteins and eleven were of soyabean origin (trypsin inhibitor, glycinin, $\beta$-conglycinin and albumin) at 10\% adulteration level. $\beta$-conglycinin, $\alpha$ and $\beta$ subunits were identified as the markers for the detection of adulterated milk as they could be detected at $1 \%$ level. Principal component analysis helped in clearly differentiating between pure and adulterated milk (Lu et al. 2017). Plant proteins were detected in adulterated skim milk powder by LC-MS/MS analysis on a quadrupole time-of-flight MS instrument. Milk samples were adulterated at $1 \& 5 \%$ levels of SPI. Enrichment of the plant proteins was done by mixing the adulterated samples with borate buffer and the supernatant obtained after centrifugation was directly applied to reversed phase perfusion column. Modified porcine trypsin was added to the enriched adulterated samples for their proteolytic digestion. The identified peaks obtained from liquid chromatography were analyzed by using Q-TOF instrument. Specific proteins in the samples were identified using PLGS and NCBI NR database. Soy proteins glycinin (types G1-G5), $\beta$-conglycinin ( $\alpha$ and $\beta$ subunit), soy lipoxygenase-1, $2 \& 3$, alcohol dehydrogenase and glucose binding protein were revealed with glycinin being the predominant one. This method could detect soy proteins at concentrations below $1 \%$ as majority of the plant proteins were retrieved in the borate buffer thus improving the efficiency of the method (Luykx et al. 2007). Cordwener et al. (2009) developed LC-MS method using a quadrupole TOF-MS instrument to detect soy protein adulteration in SMP. Plant proteins were easily detected in the adulterated SMP samples by LC-MS analysis of the corresponding total tryptic digests. Subsequent LC-MS/ MS of the differential peptides successfully identified the adulteration of soy and pea proteins. Glycinin and $\beta$-conglycinin from soyabean were detected. The approach was advantageous as compared to other methods as the adulterations can be detected without any enrichment procedure. Flow injection mass spectrometry (FIMS) in combination with chemometrics is a handy tool for the rapid detection of soy protein adulteration in milk. The principal component analysis, partial least-squaresdiscriminant analysis and support vector machine classification models successfully differentiated between pure and adulterated milk. FIMS in combination with chemometrics detected adulteration by soyabean protein in milk within 1 min per sample at levels as low as $0.5 \%(\mathrm{w} / \mathrm{w})$. FIMS coupled with chemometrics may prove to be an effective tool to detect possible economically motivated adulteration in milk (Du et al. 2018).

\section{Miscellaneous methods}

As milk proteins can be coagulated at a certain $\mathrm{pH}$, the principle was used for detection of soymilk adulteration in milk. The $\mathrm{pH}$ range of 5.4 to 6.0 can be used to precipitate the major soy proteins (7S \& 11S) while the major milk proteins remained soluble. Coagulation was done by acid and rennet. $0.1 \mathrm{~N} \mathrm{HCl}$ was used for adjusting the $\mathrm{pH}$ of milk to 5.7 and incubated at $50^{\circ} \mathrm{C}$. Visible coagulation was observed after the incubation within $10 \mathrm{~min}$ in case of milk samples containing $10 \%$ soymilk. No visible coagulation was witnessed even after extending the incubation for $30 \mathrm{~min}$ in case of milk containing 5\% soymilk. The rennet whey obtained samples were also incubated at $50^{\circ} \mathrm{C}$. The coagulation occurred within $10 \mathrm{~min}$ for samples containing $10 \%$ soymilk while a visible coagulum was observed after an extended incubation up to $20 \mathrm{~min}$ in rennet whey samples containing $5 \%$ soymilk (Sharma et al. 2010). Turbidimetric detection of plant protein involves the extraction of these plant proteins from SMP samples. In this method, SMP samples were spiked with 0.03$3.0 \%$ by weight of plant protein isolate powders i.e. soy, wheat, rice and pea isolates. These samples after mixing with sodium tetraborate-EDTA buffer were loaded in a 96 well plate column. The pellets obtained after diluting and centrifugation were resuspended in sodium tetraborate-EDTA buffer and the absorbance was measured at $360 \pm 2 \mathrm{~nm}$ (as it gave the strongest signal) at $20^{\circ} \mathrm{C}$. Limit of detection ranged from $0.1-0.2 \%$ weight of plant protein to SMP, generally considered satisfactory for economically motivated adulteration. EDTA was used to remove the turbidity and opacity of adulterated milk. This method is a 
semi-targeted approach as it is not plant specific. Other plant proteins like zein, millet, sorghum, lupin can yield similar results due to chemical similarities among their storage proteins. The sensitivity of this method is comparable or better than that of other methods like ELISA, SDS-PAGE/CE. The simplicity of this test makes it suitable for use in poor resource environments (Scholl et al. 2014). A simple microchip-CE device was developed to detect soyabean proteins adulteration in milk. The method included on-chip protein fractionation, concentration and detection within a $\mathrm{pI}$ of 5.5-7.0. Most of the milk proteins are soluble at this $\mathrm{pH}$ as compared to soy proteins which made the detection easier. The method was able to detect $0.1 \%$ of soyabean proteins in total milk proteins within $10 \mathrm{~min}$. As compared to other methods, this method was beneficial and time-saving as it involved no sample pretreatment, lesser amount of reagents were required and was less expensive (Wu et al. 2014). Dielectric property is the intrinsic property of every material/ food commodity. It is influenced by numerous factors like chemical composition, the temperature of materials and frequency of the applied electric field. This property was utilized for detecting the adulteration of soy protein in raw goat milk. The adulterated milk samples were subjected to discrete frequencies ranging from 20 $4500 \mathrm{MHz}$ at a temperature range of $5-75^{\circ} \mathrm{C}$. Regression models were applied to co-relate permittivity with temperature and adulterated soy protein content in raw goat milk. Results indicated that dielectric constant was inversely related to the applied frequency at any temperature with a greater decrease in its value at a higher temperature than at lower one. Also, an inverse relationship was found between dielectric constant and temperature at a given frequency. The dielectric constant of milk showed a negative relation with the frequency when it was increased from $20-4500 \mathrm{MHz}$, furthermore it decreased, either on increasing the temperature or decreasing the soy protein content. A linear relationship was observed between permittivities and soy protein content. Permittivities as a function of soy protein content and temperature were explained by second-order polynomials (Zhu \& Kang, 2015).

\section{Future prospects}

In future emphasis should be laid on not only improving the existing analytical methods but also simplifying the sample preparation without which it would be difficult to automize. Further, stress should be laid on maintaining the quality of milk by using rapid and automated methods, possibly coupling with the separation techniques and eliminating or simplifying the sample preparation step. More than one analyte should be targeted for detection so as to improve the reliability of the tests and prevent false positives. Methods in which the results are independent of the processing treatment given to the product, its physicochemical and intrinsic property, minimal matrix interference should be developed. Extensive validation of the existing methods is to be done. Novel markers should be discovered to strengthen the field of analytical chemistry deployed for detecting adulteration. In the future, it is expected that the advancement in the field of analytical chemistry for milk testing will be based on modern instrumental techniques. Electronic nose technology could play an important role at industrial level to ensure product safety and quality assurance. The major obstacle faced in tackling the problem of adulteration is the failure to implement the existing methods at field level as these methods are time-consuming, expensive and requires skilled personnel to perform the tests. So a relatively cheap, quick method should be developed so that it can be applicable at the grass root level to curb adulteration. If such obstacles can be overcome, then surely we will be heading towards building a healthy society.

\section{Conclusions}

Detection of adulteration in milk is complex as the markers of adulteration in milk can vary in quantity due to various biological, climatic and agronomic factors. Moreover, processing parameters can modify or alter the natural composition of the final product. Further, its intrinsic properties can pose difficulty for setting specification ranges for various methods. Therefore, stringent specification may increase the number of false-positive results. The unscrupulous manufacturers or vendors engaged in adulteration of foods have developed the art of blending food with adulterants in such a way that they can pass the adulteration detection methods. The development of simple and economical techniques for detecting adulteration in milk having high degree of repeatability and precision, is the need of the hour.

\section{References}

Afeyan NB, Fulton SP, Gordon NF, Mazsaroff I, Varady L, Regnier FE (1990) Perfusion chromatography: an approach to purifying biomolecules. Nature Biotechnol 8(3): 203

Azad T, Ahmed S (2016) Common milk adulteration and their detection techniques. Int J Food Contam 3(1): 22

Cordewener JH, Luykx DM, Frankhuizen R, Bremer MG, Hooijerink H, America AH (2009) Untargeted LC -Q -TOF mass spectrometry method for the detection of adulterations in skimmed milk powder. $\mathrm{J}$ Sep Sci 32(8): 1216-1223

Dasso J, Lee J, Bach H, Mage RG (2002) A comparison of ELISA and flow microsphere-based assays for quantification of immunoglobulins. J Immunological Methods 263(1-2): 23-33

Du L, Lu W, Cai ZJ, Bao L, Hartmann C, Gao B, Yu LL (2018) Rapid detection of milk adulteration using intact protein flow injection mass spectrometric fingerprints combined with chemometrics. Food Chem 240: $573-578$

Espeja E, Garcia MC, Marina ML (2001) Fast detection of added soyabean proteins in cow's, goat's, and ewe's milk by perfusion reversed phase high performance liquid chromatography. J Sep Sci 24(10 11): 856864

Fox PF, McSweeney PL, Paul L (1998) Dairy chemistry and biochemistry: 21-66 \& 146-238. London: Blackie Academic \& Professional

Fulton SP, Afeyan NB, Gordon NF, Regnier FE (1991) Very high-speed separation of proteins with a $20-\mu \mathrm{m}$ reversed-phase sorbent. J Chromatogr A 547: 452-456 
Garcia MC, Marina ML (2006) Rapid detection of the addition of soyabean proteins to cheese and other dairy products by reversed-phase perfusion chromatography. Food Addit Contam 23(4): 339-347

Garcia MC, Torre M, Marina ML (1998) A perfusion reversed-phase chromatographic method for ultrarapid determination of soyabean proteins in soyabean infant formulas and soyabean milks: Method development and validation. J Chromatogr Sci 36(11): 527-534

Garcia MC, Torre M, Marina ML (2000) Characterization of commercial soyabean products by conventional and perfusion reversed-phase high-performance liquid chromatography and multivariate analysis. J Chromatogr A 881(1-2): 47-57

Gautam PB, Sharma R, Lata K, Rajput YS, Mann B (2017) Construction of a lateral flow strip for detection of soymilk in milk. J Food Sci Technol 54(13): 4213-4219

Haasnoot W, du Pre JG (2007) Luminex-based triplex immunoassay for the simultaneous detection of soy, pea, and soluble wheat proteins in milk powder. J Agric Food Chem 55(10): 3771-3777

Haasnoot W, Olieman K, Cazemier G, Verheijen R (2001) Direct biosensor immunoassays for the detection of nonmilk proteins in milk powder. $\mathrm{J}$ Agric Food Chem 49(11): 5201-5206

Hewedy MM, Smith CJ (1989) Detection of soy milk in pasteurized bovine milk. Food Hydrocolloids 3(5): 399-405

Hewedy MM, Smith CJ (1990) Modified immunoassay for the detection of soy milk in pasteurized skimmed bovine milk. Food hydrocolloids 3(6): 485-490

Jablonski JE, Moore JC, Harnly JM (2014) Nontargeted detection of adulteration of skim milk powder with foreign proteins using UHPLCUV. J Agric Food Chem 62(22): 5198-5206

Jaiswal P, Jha SN, Borah A, Gautam A, Grewal MK, Jindal G(2015) Detection and quantification of soymilk in cow-buffalo milk using Attenuated Total Reflectance Fourier Transform Infrared spectroscopy (ATRFTIR). Food Chem 168: 41-47

Krusa M, Torre M, Marina ML (2000) A reversed-phase high-performance liquid chromatographic method for the determination of soya bean proteins in bovine milks. Anal Chem 72(8): 1814-1818

Lu W, Liu J, Gao B, Lv X, Yu LL (2017) Nontargeted detection of adulterated plant proteins in raw milk by UPLC-quadrupole timeof-flight mass spectrometric proteomics combined with chemometrics. J Dairy Sci 100(9): 6980-6986

Luykx DM, Cordewener JH, Ferranti P, Frankhuizen R, Bremer MG, Hooijerink H, America AH (2007) Identification of plant proteins in adulterated skimmed milk powder by high-performance liquid chromatography-mass spectrometry. J Chromatogr A 1164(1-2): 189-197

Manso MA, Cattaneo TM, Barzaghi S, Olieman C, Lopez RF (2002) Determination of Vegetal Proteins in Milk Powder by Sodium Dodecyl Sulfate-Capillary Gel Electrophoresis: Interlaboratory Study. J AOAC Int 85(5): 1090-1095

Maraboli A, Cattaneo TMP, Giangiacomo R (2002) Detection of vegetable proteins from soy, pea and wheat isolates in milk powder by near infrared spectroscopy. J Near Infrared Spectrosc 10(1): 63-69
Marina ML, Thorogate R, Smith NW (2006) A $150 \mu \mathrm{m}$ id packed column for the separation of soyabean proteins by elution gradient $\mu$ HPLC: Simultaneous separation of soyabean proteins from cereal and milk proteins. J Sep Sci 29(7): 979-985

Molina E, Amigo L, Ramos M (1998) Detection of bovine milk proteins in soymilk by Western blotting. J food prot 61(12): 1691-1694

Moore J, DeVries J, Lipp M, Griffiths J, Abernethy D (2010) Total Protein Methods and Their Potential Utility to Reduce the Risk of Food Protein Adulteration. Compr Rev Food Sci Food Saf 9: 330"357

Perez MD, Mills ENC, Lambert N, Johnson IT, Morgan MRA (2000) The use of anti soya globulin antisera in investigating soya digestion in vivo. J Sci Food Agric 80(4): 513-521

Poms RE, Klein CL, Anklam E (2004) Methods for allergen analysis in food: a review. Food Addit Contam 21(1): 1-31

Rozenfeld P, Docena GH, Fossati, MAC (2002) Detection and identification of a soy protein component that cross reacts with caseins from cow's milk. Clin Exp Immunol 130(1): 49-58

Saz JM, Marina ML (2007) High performance liquid chromatography and capillary electrophoresis in the analysis of soyabean proteins and peptides in foodstuffs. J Sep Sci 30(4): 431-451

Scholl PF, Farri SM, Mossoba MM (2014) Rapid turbidimetric detection of milk powder adulteration with plant proteins. J Agric Food Chem 62(7): 1498-1505

Sharma R, Rajput YS (2010) Methods for detection of soymilk adulteration in milk. Milchwissenschaft 65(2): 157-160

Sharma R, Rajput YS, Dogra G, Tomar SK (2009) Estimation of sugars in milk by HPLC and its application in detection of adulteration of milk with soymilk. Int J Dairy Technol 62(4): 514-519

Tapia JL, Garcia MR, Manso MA, Lopez RF (1999) Detection of the presence of soya protein in milk powder by sodium dodecyl sulfate capillary electrophoresis. J Chromatogr A 836(1): 153-160

Wang Y, Deng R, Zhang G, Li Q, Yang J, Sun Y, Li Z, Hu X (2015) Rapid and sensitive detection of the food allergen glycinin in powdered milk using a lateral flow colloidal gold immunoassay strip test. J Agricu Food Chem 63(8): 2172-2178

Wang YC, Yu RC, Yang HY, Chou CC (2003) Sugar and acid contents in soymilk fermented with lactic acid bacteria alone or simultaneously with bifidobacteria. Food Microbiol 20(3): 333-338

Wu R, Wang Z, Fung YS, Peng Seah DY, Yeung WSB (2014) Assessment of adulteration of soyabean proteins in dairy products by $2 \mathrm{D}$ microchip CE device. Electrophoresis 35(11): 1728-1734

Yang J, Zheng N, Yang Y, Wang J, Soyeurt H (2018) Detection of plant protein adulterated in fluid milk using two-dimensional gel electrophoresis combined with mass spectrometry. J Food Sci Technol 55(7): 2721-2728

Zhang Y, Kershaw J, Ainsworth P (1996) Qualitative changes in soy proteins in the production of soya cheese. Special Publication-Royal Society of Chem 179(1): 289-292

Zhu X, Kang F (2015) Frequency-and temperature-dependent dielectric properties of goat's milk adulterated with soy protein. Food Biop Technol 8(11): 2341-2346 